\title{
Gastroesophageal Reflux Disease Is Not Associated With Jackhammer Esophagus: A Case-control Study
}

\author{
Matthew Woo, ${ }^{*}$ Andy Liu, Lynn Wilsack, Dorothy Li, Milli Gupta, Yasmin Nasser, Michelle Buresi, Michael Curley, and Christopher \\ N Andrews \\ ${ }^{1}$ Division of Gastroenterology, Cumming School of Medicine, University of Calgary, Calgary, Canada
}

\begin{abstract}
Background/Aims
The pathophysiology of jackhammer esophagus (JE) remains unknown but may be related to gastroesophageal reflux disease or medication use. We aim to determine if pathologic acid exposure or the use of specific classes of medications (based on the mechanism of action) is associated with JE.

\section{Methods}

High-resolution manometry (HRM) studies from November 2013 to March 2019 with a diagnosis of JE were identified and compared to symptomatic control patients with normal HRM. Esophageal acid exposure and medication use were compared between groups. Multivariate regression analysis was performed to look for predictors of mean distal contractile integral.
\end{abstract}

\section{Results}

Forty-two JE and 127 control patients were included in the study. Twenty-two (52\%) JE and 82 (65\%) control patients underwent both HRM and ambulatory pH monitoring. Two (9\%) JE patients and $14(17 \%)$ of controls had evidence of abnormal acid exposure (DeMeester score $>14.7)$; this difference was not significant $(P=0.290)$. Thirty-six $(86 \%) \mathrm{JE}$ and $127(100 \%)$ control patients had complete medication lists. Significantly more JE patients were on long-acting beta agonists (LABA) (JE $=5$, control $=4 ; P=0.026)$ and calcium channel blockers (CCB) (JE $=5$, control $=3 ; P=0.014)$. Regular opioids $(\beta=0.298, P=0.042), C C B(\beta=0.308, P$ $=0.035)$, and inhaled anticholinergics $(\beta=0.361, P=0.049)$ predicted mean distal contractile integral $\left(R^{2}=0.082, F=4.8 ; P=\right.$ $0.003)$.

\section{Conclusions}

Pathologic acid exposure does not appear to be associated with JE. JE patients had increased CCB and LABA use. The unexpected finding of increased LABA use warrants more investigation and may provide support for a cholinergic etiology of JE.

(J Neurogastroenterol Motil 2020;26:224-231)

\section{Key Words}

Gastroesophageal reflux; Humans; Manometry

Received: April 30, 2019 Revised: June 27, 2019 Accepted: September 20, 2019

@ This is an Open Access article distributed under the terms of the Creative Commons Attribution Non-Commercial License (http:// creativecommons. org/licenses/by-nc/4.0) which permits unrestricted non-commercial use, distribution, and reproduction in any medium, provided the original work is properly cited.

${ }^{*}$ Correspondence: Matthew Woo, MD, FRCPC

Calgary Gut Motility Center, Division of Gastroenterology, Department of Medicine, University of Calgary, 3330 Hospital Dr. NW,

Calgary, AB T2N 4N1, Canada

Tel: +1-613-583-2520, E-mail: mwoo@qmed.ca 


\section{Introduction}

Jackhammer esophagus (JE) is a relatively rare diagnosis appearing in only $4 \%$ of patients referred to a tertiary center for esophageal motility testing. ${ }^{1,2}$ Although dysphagia and chest pain are common in JE patients, dysphagia has been demonstrated to correlate with contractile vigor. ${ }^{3}$

The pathophysiology of jackhammer contractions is poorly understood, but multiple theories have been proposed. Early acid perfusion studies have demonstrated the ability of acid to induce esophageal spasms, suggesting a role for gastroesophageal acid reflux (GERD) in the pathogenesis of JE., This theory has been supported by the higher than expected rate of GERD seen in JE patients, and the observation that hypertensive peristalsis has been shown to improve with suppression of gastric acid. ${ }^{2,46}$

Furthermore, JE may be related to a hypercholinergic state. This theory is supported by several observations. Hypertensive contractions arising from temporal asynchrony between contractions of circular and longitudinal esophageal muscle layers can be reversed with atropine. ${ }^{7,8}$ These abnormal contractions have also been observed in patients following vagal nerve injury. ${ }^{9}$ Lastly, diabetics with autonomic neuropathy had a higher frequency of multipeaked waves compared to patients without neuropathy, and these were reversed with atropine. ${ }^{10}$ Patients with nutcracker esophagus have also been shown to have abnormal neural inhibition with multiple rapid swallows, suggesting an underlying disorder of the enteric nervous system. ${ }^{11}$ Patients with spastic motor disorders of the esophagus have been shown to have thicker esophageal muscle, suggesting an element of outlet obstruction, and JE has been demonstrated in some cases to progress to achalasia. ${ }^{12-14}$

$\mathrm{JE}$ is thought to be associated with mechanical esophagogastric junction (EGJ) outflow obstruction, reflux disease, primary esophageal muscle hyperactivity, distal esophageal diverticula, and opioid medications. ${ }^{2,5,15}$ Our goal is to assess the role of acid reflux and medication usage on the pathogenesis of JE.

We thus performed a retrospective case-control study comparing esophageal $\mathrm{pH}$ exposure and medication use between patients with JE and symptomatic controls (SCs) with normal esophageal manometry.

\section{Materials and Methods}

\section{Patient Selection}

Consecutive high-resolution manometry (HRM) studies from symptomatic patients referred for motility testing at the Calgary Gut Motility Center (Calgary, Canada), who consented to have HRM data retrospectively analyzed are included in the Calgary Motility Databank (REB15-1331). This databank contains deidentified manometric data and medication lists, but no other patient information (such as comorbidities or subsequent treatments).

From this databank, adults ( $>18$ years of age) who underwent HRM between April 2014 and March 2019 were included in the study. All patients underwent gastroscopy prior to HRM; all patients with a structural cause of dysphagia were excluded. The study was conducted with approval by the conjoint health research ethics board at the University of Calgary (REB18-1480).

HRM studies were reviewed and interpreted as per Chicago classification version 3.0 (v3.0). Studies were identified as "jackhammer esophagus" if they had $\geq 20 \%$ of swallows with a distal contractile integral (DCI) $>8000 \mathrm{mmHg} \cdot \mathrm{sec} \cdot \mathrm{cm}$ and normal relaxation of the lower esophageal sphincter (LES; integrated relaxation pressure $[\mathrm{IRP}] \leq 15 \mathrm{mmHg}){ }^{16}$ They were compared to "SC patients" defined as symptomatic patients with normal manometries (no disorders of EGJ outflow obstruction, major or minor disorders of peristalsis) collected between November 2013 and March 2015. We chose symptomatic patients undergoing HRM (as opposed to asymptomatic patients) to increase the clinical generalizability of our findings.

Baseline variables such as age, gender, ambulatory $\mathrm{pH}$ study results, and medication use (if available) were collected to identify predictors of JE.

\section{High-resolution Manometry}

HRM studies were performed with a manometry catheter with 36 circumferential sensors spaced one centimeter apart (Medtronic, Minneapolis, MN, USA) inserted transnasally to span the entire length of the esophagus. After a short acclimation period, a minimum of 10 wet swallows of $5-\mathrm{mL}$ boluses of a mixture of 1:1 normal saline and apple juice were given at least 30 seconds apart from each other, in the upright position.

A subset of patients referred for manometry also underwent $\mathrm{pH}$ monitoring either with a 24-hour disposable transnasal $\mathrm{pH}$ catheter (Medtronic) or Bravo $\mathrm{pH}$ wireless capsule attached via a mucosal suction (Medtronic). A proportion of these patients underwent ambulatory $\mathrm{pH}$ monitoring on acid suppressive therapy with a proton pump inhibitor (PPI).

\section{Outcomes Measurement}

The primary outcome measure was quantifying differences, 
in terms of esophageal acid exposure, between patients with a manometric diagnosis of $\mathrm{JE}$ and symptomatic patients with normal HRM. Acid exposure was quantified by the DeMeester score, a composite score that includes 6 weighted criteria: total percent time $\mathrm{pH}<4$, percent upright time $\mathrm{pH}<4$, percent supine time $\mathrm{pH}<$ 4 , number of reflux episodes, number of long reflux episodes $(>5$ minutes), and longest reflux duration. A score $>14.72$ is considered abnormal. ${ }^{17}$ The $\%$ of total time $\mathrm{pH}<4$ and total number of long reflux episodes are considered the most sensitive parameters. ${ }^{18}$ We included SC patients with pathologic acid exposure and normal manometries, as motor abnormalities in GERD may not necessarily involve the tubular esophagus, and we wanted to have a clinically representative control group. ${ }^{19}$

Secondary outcomes included: (1) examining differences between $\mathrm{JE}$ and control patients in terms of medication use, and (2) examining predictors of mean DCI. Medication classes were chosen a priori for analysis and had a pathophysiologic basis for affecting esophageal peristalsis by mechanism of action.

\section{Statistical Methods}

Data are presented as frequencies (percentages) or median (range). Comparisons between groups were performed using Fisher's exact or Pearson's chi-squared in the case of categorical variables, or ANOVA in the case of continuous variables. Odds ratios (95\% CI) were calculated for medication usage. Stepwise logistic linear regression was performed to determine predictors of mean DCI. A logarithmic transformation was performed on the outcome variable as it was not normally distributed. A 2-sided $P$-value $<0.05$ was significant for all calculations. Calculations were done in SPSS version 23 (IBM, New York, USA).

\section{Results}

\section{Baseline Characteristics and High-resolution Manometry}

Three thousand three hundred thirty-one patients underwent HRM between April 2014 and March 2019 and provided consent to having their data retrospectively analyzed. Of these, 42 patients (1.3\%) met the criteria for JE and were compared to $127 \mathrm{SC}$ patients.

There was no significant difference in age or sex between the $\mathrm{JE}$ or SC groups. The JE patients' primary complaints were dysphagia (52\%) and chest pain (24\%). Significantly more JE patients presented with dysphagia ( $52 \%$ vs $31 \%, P=0.010$ ), but the other
Table 1. Demographics

\begin{tabular}{lccc}
\hline Patient Characteristics & $\mathrm{JE}(\mathrm{n}=42)$ & Control $(\mathrm{n}=127)$ & $P$-value \\
\hline Age (yr) & $56.2(10.8)$ & $52.5(13.3)$ & 0.105 \\
Female sex & $28(67)$ & $87(69)$ & 0.850 \\
Presenting symptom & & & \\
Dysphagia & $22(52)$ & $39(31)$ & $0.016^{\mathrm{a}}$ \\
Chest pain & $10(24)$ & $25(20)$ & 0.661 \\
Heartburn/dyspepsia & $7(17)$ & $37(29)$ & 0.155 \\
Cough/wheeze/globus & $3(7)$ & $21(17)$ & 0.201 \\
Other & $0(0)$ & $5(4)$ & 0.334 \\
\hline
\end{tabular}

${ }^{\mathrm{a}} \mathrm{P}<0.05$ is considered significant.

$\mathrm{JE}$, jackhammer esophagus.

Data are presented as mean (SD) or number (\%).

presenting symptoms were similar between groups. See Table 1 for further demographic details. The distal latency, mean DCI, maximum DCI, basal LES pressure, IRP, and incomplete bolus clearance were all significantly higher in patients with $\mathrm{JE}$ when compared to SC. (Table 2).

\section{Esophageal Acid Exposure}

Twenty-two (52\%) JE and 82 (65\%) SC patients underwent both HRM and ambulatory pH monitoring. Two (9\%) JE and 14 (17\%) SC patients had evidence of abnormal acid exposure (defined as a DeMeester score $>14.7)$; this difference was not significant $(P=0.290)$. There were no differences seen in any other acid reflux parameters (Table 3). There were no significant differences seen in PPI use between groups (JE 11 patients [50\%] vs SC 42 [51\%], $P=0.555$ ).

\section{Medication Use}

Thirty-six (86\%) JE and 127 (100\%) SC patients had complete medication lists. In terms of medications, significantly more $\mathrm{JE}$ patients were on $\mathrm{LABA}(\mathrm{JE}=5, \mathrm{SC}=4 ; P=0.026$, OR 5.0 [1.3-19.6]) and calcium channel blockers (CCBs) (JE $=5, \mathrm{SC}$ $=3 ; P=0.014$, OR $6.7[1.5-29.4])$. There was no significant difference in age or gender between JE and SC patients, who were on LABA or CCBs. No other medication classes were significantly different between groups (Table 4).

Three variables predicted mean DCI $\left(\mathrm{R}^{2}=0.082, \mathrm{~F}=4.8\right.$, $P=0.003)$. Regular opioids $(\beta=0.298, P=0.042,95 \% \mathrm{CI}=$ $0.010-0.586), \mathrm{CCB}(\beta=0.308, P=0.035,95 \% \mathrm{CI}=0.022-$ $0.593)$, and inhaled anticholinergics $(\beta=0.361, P=0.049,95 \%$ $\mathrm{CI}=0.001-0.721)$ were included in the regression equation. Sex, age, prokinetics, selective norepinephrine receptor inhibitor, beta blockers, and LABA were excluded from the equation. The final model including regular opioids, $\mathrm{CCB}$, and inhaled anticholiner- 
Table 2. Comparison of Manometric Parameters Between Jackhammer Esophagus and Control Group

\begin{tabular}{lccc}
\hline \multicolumn{1}{c}{ HRM parameter } & JE $(\mathrm{n}=42)$ & Control $(\mathrm{n}=127)$ & $P$-value \\
\hline LES basal pressure $(\mathrm{mmHg})$ & $36.9(12.4-78)$ & $27.5(8.5-96.4)$ & $0.002^{\mathrm{a}}$ \\
LES residual pressure $(\mathrm{mmHg})$ & $10.9(-17.4-15.0)$ & $5.9(-4.3-14.9)$ & $<0.001^{\mathrm{a}}$ \\
Mean DCI $(\mathrm{mmHg} \cdot \mathrm{sec} \cdot \mathrm{cm})$ & $6681.5(3450-16020.4)$ & $1127.4(1322.9-4168.3)$ & $<0.001^{\mathrm{a}}$ \\
Maximum DCI $(\mathrm{mmHg} \cdot \mathrm{sec} \cdot \mathrm{cm})$ & $12354.5(8280.9-33673.2)$ & $2195.6(436.0-7110.3)$ & $<0.001^{\mathrm{a}}$ \\
Distal latency $(\mathrm{sec})$ & $7.8(5.5-16.7)$ & $6.9(5.0-11.1)$ & $<0.001^{\mathrm{a}}$ \\
Incomplete bolus clearance $(\%)$ & $10.0(0.0-100.0)$ & $10.0(0.0-100.0)$ & $0.018^{\mathrm{a}}$ \\
\hline
\end{tabular}

${ }^{\mathrm{a} P}<0.05$ is considered significant.

HRM, high-resolution manometry; LES, lower esophageal sphincter; DCI, distal contractile integral.

Data are presented as median (interquartile range).

Table 3. Comparison of $\mathrm{pH}$ Parameters Between Jackhammer Esophagus and Control Group

\begin{tabular}{lccc}
\hline \multicolumn{1}{c}{ pH parameter } & JE $(\mathrm{n}=22)$ & Control $(\mathrm{n}=82)$ & $P$-value \\
\hline PPI use & $11(50)$ & $42(51)$ & 0.999 \\
DeMeester score & $2.6(0.8-29.6)$ & $5.3(0.8-148.7)$ & 0.166 \\
Total acid exposure time (\%) & $0.55(0.0-7.9)$ & $1.5(0.0-40.2)$ & 0.154 \\
Upright acid exposure time (\%) & $0.9(0.0-15.8)$ & $2.2(0.0-36.7)$ & 0.315 \\
Supine acid exposure time (\%) & $0(0.0-3.3)$ & $0(0.0-43.8)$ & 0.168 \\
Longest reflux episode (min) & $3.0(0.0-35.0)$ & $4.5(0.0-90.3)$ & 0.439 \\
Number of acid reflux episodes on impedance (n) & $8.5(0.0-80.0)$ & $13(0.0-84.0)$ & 0.430 \\
Non-acid reflux episodes on impedance (n) & $0(0.0-355.0)$ & $24(1.0-88.0)$ & 0.673 \\
\hline
\end{tabular}

JE, jackhammer esophagus; PPI, proton pump inhibitor.

Data are presented as number $(\%)$ or median (range).

Table 4. Comparison of Medications Between Jackhammer Esophagus and Control Group

\begin{tabular}{lcccc}
\hline \multicolumn{1}{c}{ Medications } & $\mathrm{JE}(\mathrm{n}=36)$ & Control $(\mathrm{n}=127)$ & $P$-value & OR $(95 \% \mathrm{CI})$ \\
\hline Inhaled anticholinergic & 3 & 2 & 0.072 & $5.7(0.9-35.0)$ \\
PPI & 24 & 78 & 0.697 & $1.3(0.6-2.7)$ \\
Opioid & 4 & 4 & 0.072 & $3.8(0.9-16.0)$ \\
SNRI (selective norepinephrine receptor inhibitor) & 3 & 6 & 0.316 & $1.8(0.4-7.7)$ \\
Calcium channel blocker & 5 & 3 & $0.014^{\mathrm{a}}$ & $6.7(1.5-29.4)$ \\
TCA & 3 & 10 & $>0.999$ & $1.1(0.3-4.1)$ \\
Beta-blocker & 5 & 13 & 0.551 & $1.4(0.5-4.3)$ \\
Prokinetic & 1 & 10 & 0.459 & $0.3(0.0-2.7)$ \\
LABA & 5 & 4 & $0.026^{\mathrm{a}}$ & $5.0(1.3-19.6)$ \\
\hline
\end{tabular}

${ }^{a} P<0.05$ is considered significant.

JE, jackhammer esophagus; PPI, proton pump inhibitor; TCA, tricyclic antidepressant; LABA, long-acting beta agonist.

Data are presented as number.

gics accounted for $8.2 \%$ of the variance in mean DCI.

\section{Discussion}

We performed a retrospective case-control study comparing esophageal acid exposure in patients with JE vs SC patients with normal HRM. A secondary analysis was performed to examine medication usage between both groups. Our analysis demonstrated that patients with JE do not appear to have an increased incidence of abnormal acid exposure. Furthermore, more JE patients were on LABA, and CCBs compared to SC. Regular opioid use, CCBs, and inhaled anticholinergics were positive predictors of DCI.

Strengths of this study include the fact that although this study was retrospective, all manometries were reviewed to ensure they met 
the Chicago classification v3.0 definition of JE, which demonstrates higher specificity and symptom correlation. ${ }^{16}$ Furthermore, we excluded patients with outflow obstruction, as per Chicago classification v3.0. ${ }^{16}$

However, our study has several weaknesses that must be acknowledged. Given our use of a deidentified HRM database, we did not have access to patient's medical comorbidity information. This made it challenging to eliminate the possibility of specific comorbidities being confounders. Our requirement for patients to meet the Chicago classification v3.0 definition of JE may have limited our study population; indeed, only $1.3 \%$ of HRMs over the study period had JE, a similar prevalence to other studies that use the same manometric criteria. ${ }^{20}$ While our study population of $42 \mathrm{JE}$ patients is one of the larger cohorts in the published literature, only 22 (52\%) had ambulatory $\mathrm{pH}$ testing and 36 (86\%) had medication lists. Furthermore, we included a diverse group of patients with multiple comorbidities; thus many of the medications were present at low frequencies. As a result, even small changes in the distribution of medications in either the JE or SC groups may change our conclusions. The low numbers may have prevented us from detecting a significant difference in other medication classes and increases the likelihood of spurious findings; a limitation present in many retrospective studies that seek to examine the contribution of medications to gastrointestinal motility disorders. Lastly, we did not collect doses of medications, which prevents us from establishing any dose-response relationship and while patient's symptoms were reported at the time of HRM, we did not use validated symptom indices, which prevents us from assessing the severity of symptomology. Thus, our results and conclusions must be interpreted with caution.

\section{Gastroesophageal Reflux Disease and Jackhammer Esophagus}

While gastroesophageal reflux has been implicated as a possible causative factor, based on the higher than expected incidence of GERD in patients with JE than seen in previous studies (43-47\%), our research finds no association between distal esophageal acid exposure and $\mathrm{JE}^{4,6}$

Manometric resolution of JE has been documented in patients undergoing PPI therapy. ${ }^{2}$ This lead to the suggestion that an empiric PPI trial may be reasonable. ${ }^{21}$ However, published data are conflicting. Mallet et $\mathrm{al}^{4}$ found that PPI use was not associated with symptomatic improvement in a cohort of JE patients (with and without GERD) who underwent PPI therapy for a median of 21 months. However, repeat manometry was not performed in these patients. A more recent study looked at $41 \mathrm{JE}$ patients selected from a cohort of patients referred for anti-reflux surgery and found that similar proportions ( $43.2 \%$ ) had GERD, compared to those without GERD, and there was no significant difference in PPI use between groups. ${ }^{20}$

The prevalence of abnormal acid exposure in our cohort (7.7\%) was significantly lower than previously demonstrated, but most JE patients (65.3\%) were on PPIs. Due to technical limitations, ambulatory $\mathrm{pH}$ studies did not report weakly acid reflux episodes, nor acid/weakly acid exposure time on impedance; however, there was no significant difference between total acid and non-acid reflux episodes on the studies with impedance monitoring. Thus, our interpretation is 2-fold; GERD does not appear to be more common in JE patients compared to SC, and if GERD is to be implicated in the pathogenesis of JE, correction of esophageal acidification does not appear to cause resolution of hypercontractile peristalsis.

\section{Medication Use and Jackhammer Esophagus}

Unexpectedly, significantly more JE patients were on CCBs and LABA compared to SC patients. Furthermore, regular opioid, calcium channel blocker, and inhaled anticholinergics were all positive predictors of mean DCI.

Our finding of increased CCB may be spurious. In a prospective placebo-controlled trial of 5 healthy volunteers and 10 nutcracker esophagus patients, oral CCB use was demonstrated to decrease the amplitude and duration of esophageal peristalsis in patients with nutcracker esophagus, although this reduction was not seen when compared to placebo. ${ }^{22}$ For this reason, CCB is often empirically used in the management of non-obstructive dysphagia and non-cardiac chest pain.

However, this paradoxical observation has been seen in other similar studies seeking to elucidate the role of medications in hypercontractile esophagus. Schupack et $\mathrm{al}^{23}$ noted that smooth muscle relaxant medications (including calcium channel blockers) were significantly more common at presentation in 40 patients with hypercontractile esophagus compared to 33 symptomatic controls with normal HRM ( $20 \%$ vs $0 \%, P=0.007)$. Furthermore Kamal et al ${ }^{24}$ reported that 4/13 (30.8\%) patients with hypermotility esophageal disorders were on $\mathrm{CCB}$, although this was not significantly different compared to healthy controls. It is conceivable that symptomatic patients in whom a motility disorder is being questioned may undergo a CCB trial prior to HRM.

The finding of increased LABA use is also unexpected, given that oral and inhaled beta-adrenergic stimulation has been previously demonstrated to reduce LES pressure and contractile ampli- 
tude of esophageal peristalsis in healthy patients. ${ }^{24-27}$ However, there is evidence that the genesis of jackhammer contractions is different than normal esophageal peristalsis and may involve a hypercholinergic state. $^{7-10}$

The observed association between beta-agonist use and JE may be explained by modulation of acetylcholine signaling. Cholinergic excess, causing bronchoconstriction, has been implicated in increased mortality in asthma patients on LABA alone. This is supported by studies that show that in rat airway smooth muscle cells, persistent administration of beta- 2 adrenergic agonists appears to mediate upregulation of muscarinic $\mathrm{M}_{3}$ receptors by a beta-2 adrenoceptor/cyclic adenosine monophosphate signaling pathway. ${ }^{29}$ Muscarinic $\mathrm{M}_{3}$ receptors have been shown to induce contraction in human esophageal smooth muscle, and upregulation of these cholinergic receptors may result in hypertensive peristalsis. ${ }^{30}$

On the other hand, our finding may be confounded by the fact that LABA are generally used in the management of obstructive airway disease (eg, asthma or chronic obstructive pulmonary disease $[\mathrm{COPD}])$. Patients with asthma may be more likely to have $\mathrm{JE}$ due to a hypercholinergic state. Acetylcholine is well known to play a role in asthma. Both animal and human models of allergic airway inflammation and asthma have implicated muscarinic $\mathrm{M}_{2}$ autoreceptor dysfunction in the exaggerated acetylcholine release seen in bronchial hypersensitivity. ${ }^{31}$ However, an increased $\mathrm{M}_{3}$ receptor abundance in canine tracheal myocytes is associated with an increased contractile phenotype, with significant shortening on acetylcholine exposure. ${ }^{32}$ Thus, patients with asthma and bronchial smooth muscle hyperreactivity may be more likely to have $\mathrm{M}_{3}$ mediated hypercontractility of the smooth muscle. Furthermore, there is evidence that a subset of asthmatics may have cholinergic hypersensitivity. This may be due to the common embryological origin of the bronchial tree and the esophagus. ${ }^{33}$ Asthmatics with GERD have evidence of systemic cholinergic hyperresponsiveness, based on hypervagal response on autonomic testing. ${ }^{34,35}$ Unfortunately, we did not collect comorbidity information on our patients which prevents us from testing this inference; however, the indication for LABA would most likely be reactive airway disease (either asthma or COPD).

Our findings of regular opioid use and inhaled anticholinergic use being a positive predictor of mean DCI overlap with what has been previously observed in the literature. The finding of opioid users having a higher DCI compared to non-users was observed by Ratuapli et $\mathrm{al}^{36}$ in a retrospective review of 121 chronic opioid users. Oral anticholinergics have been previously documented to decrease upright, post-prandial, esophageal peristaltic amplitude in healthy humans. ${ }^{37}$ However, contrary to this, Schupack et $\mathrm{al}^{23}$ found that $75 \%$ of 56 patients with EGJ outflow obstruction and 40 patients with hypertensive esophagus were on oral anticholinergic medications. While they were not able to generate a plausible mechanistic association, they postulated that prior local evaluation resulting in nonspecific HRM findings could have lead to the initiation of anticholinergic medications such as Tricyclic antidepressants. In our case, this unexpected finding could be explained by in a similar fashion to the unexpectedly high number of patients on LABAs the presence of reactive airway disease being a confounder. The low level of variance in DCI (8.2\%) accounted for by the regression equation supports the complexity of modulation of esophageal peristalsis.

\section{Manometric Parameters in Jackhammer Esophagus}

We found that patients with JE had a significantly higher basal LES, IRP, and distal latency than patients with normal esophageal manometries. This relationship was also observed by Schupack et $\mathrm{al}^{23}$ Herregods et $\mathrm{al}^{3}$ also noted that DCI correlated with IRP in a cohort of patients with JE. A normally-functioning esophagus should vigorously contract to propel bolus past a mechanical obstruction. The elevated LES and IRP may thus suggest an element of outflow obstruction in JE, not meeting the criteria for EGJ outflow obstruction (IRP > $15 \mathrm{mmHg}$ ). ${ }^{16}$ Conversely, this could also suggest a loss of inhibitory input. ${ }^{23}$

The finding of dysphagia being significantly more common in JE compared to SC patients is in keeping with findings of Herregods et $\mathrm{al}^{3}$ who observed that dysphagia, but not chest pain, correlated with contractile vigor in a cohort of 34 patients with JE.

\section{Conclusion}

In summary, patients with JE do not appear to have an increased incidence of pathologic acid exposure compared to symptomatic patients with normal HRM. Our study demonstrated increased LABA and CCB use among JE patients. This unexpected finding may yield some insight into the pathophysiology of $\mathrm{JE}$, which is still poorly understood. To better understand their role, assessing esophageal function in patients who are on long-term LABA (eg, asthma patients) prospectively is required.

Financial support: None.

Conflicts of interest: None.

Author contributions: Matthew Woo is the guarantor of this 
article. All authors participated in the creation of this original article. Matthew Woo designed the study, collected data, analyzed and interpreted data, and drafted the manuscript; Andy Liu and Lynn Wilsack designed the study and collected data; Dorothy Li, Milli Gupta, Michelle Buresi, Yasmin Nasser, and Michael Curley analyzed and interpreted data; and Christopher $\mathrm{N}$ Andrews designed the study, and analyzed and interpreted data. All authors critically revised the manuscript for important intellectual content and approved the final manuscript.

\section{References}

1. Jia Y, Arenas J, Hejazi RA, Elhanafi S, Saadi M, McCallum RW. Frequency of jackhammer esophagus as the extreme phenotypes of esophageal hypercontractility based on the new chicago classification. J Clin Gastroenterol 2016;50:615-618.

2. Roman S, Pandolfino JE, Chen J, Boris L, Luger D, Kahrilas PJ. Phenotypes and clinical context of hypercontractability in high resolution esophageal pressure topography (EPT). Am J Gastroenterol 2012;107:37-45.

3. Herregods TV, Smout AJ, Ooi JL, Sifrim D, Bredenoord AJ. Jackhammer esophagus: observations on a european cohort. Neurogastroenterol Motil 2017;29:e12975.

4. Mallet AL, Ropert A, Bouguen G, et al. Prevalence and characteristics of acid gastro-oesophageal reflux disease in jackhammer oesophagus. Dig Liver Dis 2016;48:1136-1141.

5. Kristo I, Schwameis K, Maschke S, et al. Phenotypes of jackhammer esophagus in patients with typical symptoms of gastroesophageal reflux disease responsive to proton pump inhibitors. Sci Rep 2018;8:9949.

6. Börjesson M, Pilhall M, Rolny P, Mannheimer C. Gastroesophageal acid reflux in patients with nutcracker esophagus. Scand J Gastroenterol 2001;36:916-920.

7. Jung HY, Puckett JL, Bhalla V, et al. Asynchrony between the circular and the longitudinal muscle contraction in patients with nutcracker esophagus. Gastroenterology 2005;128:1179-1186.

8. Korsapati H, Bhargava V, Mittal RK. Reversal of asynchrony between circular and longitudinal muscle contraction in nutcracker esophagus by atropine. Gastroenterology 2008;135:796-802.

9. Tolone S, Savarino E, Docimo L. Radiofrequency catheter ablation for atrial fibrillation elicited "Jachammer esophagus": a new complication due to vagal nerve stimulation?. J Neurogastroenterol Motil 2015;21:612-615.

10. Loo FD, Dodds WJ, Soergel KH, Arndorfer RC, Helm JF, Hogan WJ. Multipeaked esophageal peristaltic pressure waves in patients with diabetic neuropathy. Gastroenterology 1985;88:485-491.

11. Brito EM, Camacho-Lobato L, Paoletti V, Gideon M, Katz PO, Castell DO. Effect of different swallow time intervals on the nutcracker esophagus. Am J Gastroenterol 2003;98:40-45.

12. Huang L, Pimentel M, Rezaie A. Do jackhammer contractions lead to achalasia? A longitudinal study. Neurogastroenterol Motil 2017;29:e12953.
13. Abdallah J, Fass R. Progression of jackhammer esophagus to achalasia: author's reply. J Neurogastroenterol Motil 2016;22:350.

14. Dogan I, Puckett JL, Padda BS, Mittal RK. Prevalence of increased esophageal muscle thickness in patients with esophageal symptoms. Am J Gastroenterol 2007;102:137-145.

15. Al-Qaisi MT, Siddiki HA, Crowell MD, et al. The clinical significance of hypercontractile peristalsis: comparison of high-resolution manometric features, demographics, symptom presentation, and response to therapy in patients with jackhammer esophagus versus nutcracker esophagus. Dis Esophagus 2017;30:1-7.

16. Kahrilas PJ, Bredenoord AJ, Fox M, et al. The Chicago classification of esophageal motility disorders, v3.0. Neurogastroenterol Motil 2015;27:160-174.

17. Jamieson JR, Stein HJ, DeMeester TR, et al. Ambulatory 24-h esophageal $\mathrm{pH}$ monitoring: normal values, optimal thresholds, specificity, sensitivity, and reproducibility. Am J Gastroenterol 1992;87:1102-1111.

18. Johnson LF, DeMeester TR. Development of the 24-hour intraesophageal $\mathrm{pH}$ monitoring composite scoring system. J Clin Gastroenterol 1986;8(suppl 1):52-58.

19. Martinucci I, de Bortoli N, Giacchino M, et al. Esophageal motility abnormalities in gastroesophageal reflux disease. World J Gastrointest Pharmacol Ther 2014;5:86-96.

20. Kristo I, Schwameis K, Maschke S, et al. Phenotypes of Jackhammer esophagus in patients with typical symptoms of gastroesophageal reflux disease responsive to proton pump inhibitors. Sci Rep 2018;8:9949.

21. Roman S, Kahrilas P. Management of spastic disorders of the esophagus. Gastroenterol Clin North Am 2013;42:27-43.

22. Richter JE, Spurling TJ, Cordova CM, Castell DO. Effects of oral calcium blocker, diltiazem, on esophageal contractions. Studies in volunteers and patients with nutcracker esophagus. Dig Dis Sci 1984;29:649-656.

23. Schupack D, Katzka DA, Geno DM, Ravi K. The clinical significance of esophagogastric junction outflow obstruction and hypercontractile esophagus in high resolution esophageal manometry. Neurogastroenterol Motil 2017;29:1-9.

24. Kamal A, Shakya S, Lopez R, Thota PN. Gender, medication use and other factors associated with esophageal motility disorders in nonobstructive dysphagia. Gastroenterol Rep 2018;6:177-183.

25. Lyrenäs E, Abrahamsson H. Beta adrenergic influence on oesophageal peristalsis in man. Gut 1986;27:260-266.

26. Zfass AM, Prince R, Allen FN, Farrar JT. Inhibitory beta receptors in the human distal esophagus. Am J Dig Dis 1970;15:303-310.

27. Schindlbeck NE, Heinrich C, Huber RM, Müller-Lissner SA. Effects of albuterol (sabutamol) on esophageal motility and gastroesophageal reflux in healthy volunteers. JAMA 1988;260:3156-3158.

28. Crowell MD, Zayat EN, Lacy BE, Schettler-duncan A, Liu MC. The effects of an inhaled beta2 -adrenergic agonist on lower esophageal function: a dose-response study. Chest 2014;120:1184-1189.

29. Liu YH, Wu SZ, Wang G, Huang NW, Liu CT. A long-acting $\beta_{2-}$ adrenergic agonist increases the expression of muscarine cholinergic subtype- 3 receptors by activating the $\beta_{2}$-adrenoceptor cyclic adenosine monophosphate signaling pathway in airway smooth muscle cells. Mol Med Rep 2015;11:4121-4128. 
30. Preiksaitis HG, Krysiak PS, Chrones T, Rajgopal V, Laurier LG. Pharmacological and molecular characterization of muscarinic receptor subtypes in human esophageal smooth muscle. J Pharmacol Exp Ther 2000;295:879-888.

31. Gosens R, Zaagsma J, Grootte Bromhaar M, Nelemans A, Meurs H. Acetylcholine: a novel regulator of airway smooth muscle remodelling? Eur J Pharmacol 2004;500:193-201.

32. Mitchell RW, Halayko AJ, Kahraman S, Solway J, Wylam ME. Selective restoration of calcium coupling to muscarinic $\mathrm{M}_{3}$ receptors in contractile cultured airway myocytes. Am J Physiol Lung Cell Mol Physiol 2000;278:L1091-L1100.

33. Harding SM. Gastroesophageal reflux and asthma : insight into the association. J Allergy Clin Immunol 1999;104(2 Pt 1):251-259.

34. Lodi U, Harding SM, Coghlan HC, Guzzo MR, Walker LH. Au- tonomic regulation in asthmatics with gastroesophageal reflux. Chest 1997;111:65-70.

35. Amarasiri DL, Pathmeswaran A, Dassanayake AS, de Silva AP, Ranasinha CD, de Silva HJ. Esophageal motility, vagal function and gastroesophageal reflux in a cohort of adult asthmatics. BMC Gastroenterol 2012;12:140.

36. Ratuapli SK, Crowell MD, DiBaise JK, et al. Opioid-induced esophageal dysfunction (OIED) in patients on chronic opioids. Am J Gastroenterol 2015;110:979-984.

37. Koerselman J, Pursnani KG, Peghini P, et al. Different effects of an oral anticholinergic drug on gastroesophageal reflux in upright and supine position in normal, ambulant subjects: a pilot study. Am J Gastroenterol 1999;94:925-930. 